\title{
Lipopolysaccharide heterogeneity in Pasteurella haemolytica isolates from cattle and sheep
}

\author{
Q. Ali, ${ }^{1}$ R. L. Davies, ${ }^{1 *}$ R. Parton, ${ }^{1}$ J. G. Coote ${ }^{1}$ and H. A. Gibbs ${ }^{2}$ \\ Departments of Microbiology ${ }^{1}$ and Veterinary Medicine ${ }^{2}$, University of Glasgow, Glasgow G12 8QQ, UK
}

(Received 27 March 1992; revised 19 June 1992; accepted 3 July 1992)

\begin{abstract}
Lipopolysaccharide (LPS) from 40 isolates of Pasteurella haemolytica, comprising 23 serotype A1, seven serotype A2, one serotype T4, one serotype T10 and eight untypable isolates, obtained from diseased and healthy cattle or sheep, was characterized by SDS-PAGE and Western blotting. Ten different SDS-PAGE LPS profiles, five smooth and five rough, were identified among the biotype $A$ and untypable isolates and designated LPS types 1-10. L.PS types 1 and 2 were smooth, had similar $O$-antigen banding-patterns but differed in the low-molecular-mass or core-oligosaccharide regions; type 3 LPS was rough but had a core-oligosaccharide region similar to that of LPS type 1. No similarities were observed between these LPS types and types 6,7 and 9, which were smooth, and types $4,5,8$ and 10, which were rough. Most serotype A1 isolates (19/23) were of LPS type 1, whereas two isolates each had LPS of types 2 and 3. The majority (5/7) of serotype A2 isolates possessed type 3 LPS, whereas the remaining two isolates each had LPS of types 4 and 5. There was much greater heterogeneity within the untypable group of isolates, which comprised LPS of types 1 and 9 (two isolates each), and 6, 7, 8 or 10 (one isolate each). Western blotting analysis demonstrated that LPS types 1 and 2 had immunologically identical O-antigen side-chains but differed in their core-oligosaccharide regions, whereas the core-oligosaccharide region of rough LPS type 3 was immunologically very similar to that of LPS type 1. The other LPS types were immunologically unrelated to these three LPS types. The majority (20/23) of serotype A1 isolates originated from cattle and possessed LPS types 1 or 2, different from most (5/7) of the serotype A2 isolates which originated from sheep and possessed LPS of types 3 or 4. However, two of the three ovine serotype A1 isolates had the same type 3 LPS as occurred in most of the ovine serotype $\mathrm{A2}$ isolates, suggesting a possible correlation between LPS type and host specificity. This study has demonstrated that LPS diversity within different serotypes of $P$. haemolytica is greater than was previously thought and that certain LPS types might be host-specific.
\end{abstract}

\section{Introduction}

Pasteurella haemolytica is a Gram-negative bacterium responsible for diseases of ruminants, including pneumonic pasteurellosis of cattle and sheep (Carter, 1967). The bacterium is differentiated into two biotypes, $A$ and $\mathrm{T}$, based on the fermentation reactions with arabinose and trehalose, and into 16 serotypes, thought to be based on soluble capsular antigens (Biberstein, 1978; Fodor $e t$ al., 1988). Serotypes A1 and A2 are the most commonly occurring serotypes associated with pneumonic pasteur-

* Author for correspondence. Tel. (041) 3398855 ext. 5840; fax (041) 3304600 .

Abbreviations: OMP, outer-membrane protein; LPS, lipopolysaccharide. ellosis in cattle and sheep, respectively, although the reasons for this host specificity are unknown. Biotype $T$ strains are responsible for a pathologically distinct systemic infection of young adult sheep (Gilmour \& Gilmour, 1989). Approximately $10 \%$ of all isolates from sheep and cattle are untypable (Biberstein et al., 1960).

Although the method of serotyping $P$. haemolytica, by indirect haemagglutination assay (Biberstein et al., 1960), is adequate for most purposes, the method of preparation of the antigens is extremely crude and the nature of the antigen ill-defined. Theoretically, the procedure detects immunological differences in a soluble antigen extract, presumed to be capsular polysaccharide, but it does not eliminate the possibility of cross-reactivity due to other contaminating antigens such as lipopolysaccharide (LPS). An additional disadvantage of the 
procedure is that it is unable to distinguish between untypable isolates of $P$. haemolytica, which are thought to be without capsular material (Aarsleff et al., 1970; Biberstein, 1978). Other methods of serotyping have been attempted including agglutination of autoclaved cells (Biberstein et al., 1960; Aarsleff et al., 1970), rapid plate agglutination (Frank \& Wessman, 1978) and counter current immunoelectrophoresis (Chengappa et al., 1984) but none of these has met with great success and become widely adopted. However, Frank (1980) identified three distinct serotypes among 10 untypable $P$. haemolytica isolates by rapid plate agglutination, whereas Donachie et al. (1984) were able to distinguish nine serogroups among 30 untypable isolates using counter current immunoelectrophoresis. Both authors suggested that the untypable $P$. haemolytica isolates were antigenically distinct and not variants of serotypes deficient in the capsular antigen as was speculated by Aarsleff et al. (1970) and Biberstein (1978).

The LPS of Gram-negative bacteria, and of the Enterobacteriaceae in particular, is responsible for the determination of O-serotypes and may be used in differentiating between strains of a given bacterial species and between different species (Ørskov \& Ørskov, 1978). The LPS molecule consists of three regions: (i) lipid A, (ii) the oligosaccharide core, composed of approximately 10 monosaccharides; (iii) the $\mathrm{O}$-specific antigen or somatic antigen, consisting of repeating units of from one to seven monosaccharides (Hitchcock et al., 1986). When analysed by SDS-PAGE and silverstaining, smooth-type LPS is separated into a lowmolecular-mass fraction, consisting of the lipid Aoligosaccharide core region, and a distinctive ladderpattern of high-molecular-mass bands representing molecules of increasing molecular mass as additional $\mathrm{O}$-antigen units are added to the basic core structure. Rough LPS, consisting only of the core-oligosaccharidelipid A region, is visualized as a number of lowmolecular-mass bands only. The profile of a given LPS type in a silver-stained SDS-polyacrylamide gel is a characteristic of that particular bacterial species or serotype and is related to the chemical composition and structure of the LPS (Hitchcock \& Brown, 1983). Characterization of the LPS profiles of large numbers of isolates of a given bacterial species is able to identify strain differences and subtypes within that species and such analyses have proved extremely useful in epidemiological and virulence studies (Inzana, 1983; Tsai et al., 1983; Lugtenberg et al., 1984; Rimler, 1990). Variation in LPS structure can be further analysed by examining antigenic differences by Western blotting (Karch et al., 1984; Sturm et al., 1984; Manning et al., 1986; Preston \& Penner, 1987; Tsai et al., 1987).

The LPS of P. haemolytica has not been widely studied.
LPS from different serotypes is known to be antigenically related (Durham et al., 1988) but little is known about variation of LPS within the species, particularly within biotype A strains. However, major differences occur in the LPS associated with the A and T biotypes. Strains belonging to the $T$ biotype have a characteristic smooth-type LPS whereas the LPS of the A biotypes has been reported to be rough (Adlam, 1989). The chemical structures of the O-chains of strains of serotypes T3, T4 and T10 have been determined (Perry \& Babiuk, 1984; Leitch \& Richards, 1988; Richards \& Leitch, 1989) but the LPS of biotype A strains has been less well characterized. However, in a previous paper, smoothtype LPS was described in two serotype Al isolates, whereas the LPS of a number of serotype A2 isolates was confirmed as being of the rough type (Davies et al., 1991). In addition, differences were described in the lowmolecular-mass region of the two serotype Al isolates, suggesting variation within serotypes. In the present study, the LPS of a larger population of isolates was studied, by SDS-PAGE and Western blotting, with the aim of gaining a better insight into the nature of the LPS of this organism.

\section{Methods}

Bacterial strains and growth conditions. Forty isolates of $P$. haemolytica including 23 serotype A1, seven serotype A2, eight untypable isolates and one isolate each of serotypes $\mathrm{T} 4$ and $\mathrm{T} 10$ were used in the present study. In addition, Pasteurella multocida NCTC 10322 was used for comparative purposes. The isolates were obtained from the nasopharynx or lower respiratory tract of diseased or healthy cattle and sheep. Details of the isolates, including biotype, serotype and source, are given in Table 1.

Bacteria, stored at $-70^{\circ} \mathrm{C}$ in brain heart infusion broth (BHIB; Oxoid) containing $50 \%(\mathrm{v} / \mathrm{v})$ glycerol, were subcultured routinely on brain heart infusion agar (BHIA; Oxoid) containing $5 \%(\mathrm{v} / \mathrm{v})$ sheep's blood at $37^{\circ} \mathrm{C}$. For LPS isolation, bacteria were grown overnight at $37^{\circ} \mathrm{C}$, to stationary phase, in BHIB with orbital shaking at 120 r.p.m.

Serotyping. Serotyping of isolates was carried out by indirect haemagglutination assay with bovine red blood cells by the method of Shreeve et al. (1972).

LPS preparation. LPS for SDS-PAGE analysis was obtained by digestion of outer-membrane preparations with proteinase $K$, and has been described previously (Davies et al., 1991). For the raising of rabbit anti-LPS antibodies, however, LPS was purified by extraction with aqueous phenol, also as described previously (Davies et al., 1991).

Antiserum production. Antisera were raised against purified LPS of isolates $\mathrm{S} / \mathrm{C} 82 / 1$ and $\mathrm{W} / \mathrm{D} 83 / 4$ in New Zealand White rabbits. LPS from these two isolates had previously been shown to be different (Davies et al., 1991). Approximately $10 \mathrm{mg}$ of LPS, dissolved in $0.5 \mathrm{ml}$ of saline $(0.9 \%, \mathrm{w} / \mathrm{v} . \mathrm{NaCl})$ and mixed with an equal volume of Freund's incomplete adjuvant, was injected subcutaneously into six sites along the back of the rabbit. Two series of injections were given, 4 weeks apart, and blood was collected 2 weeks after the second injection from the marginal ear vein. 
Table 1. Details of P. haemolytica isolates examined in the study

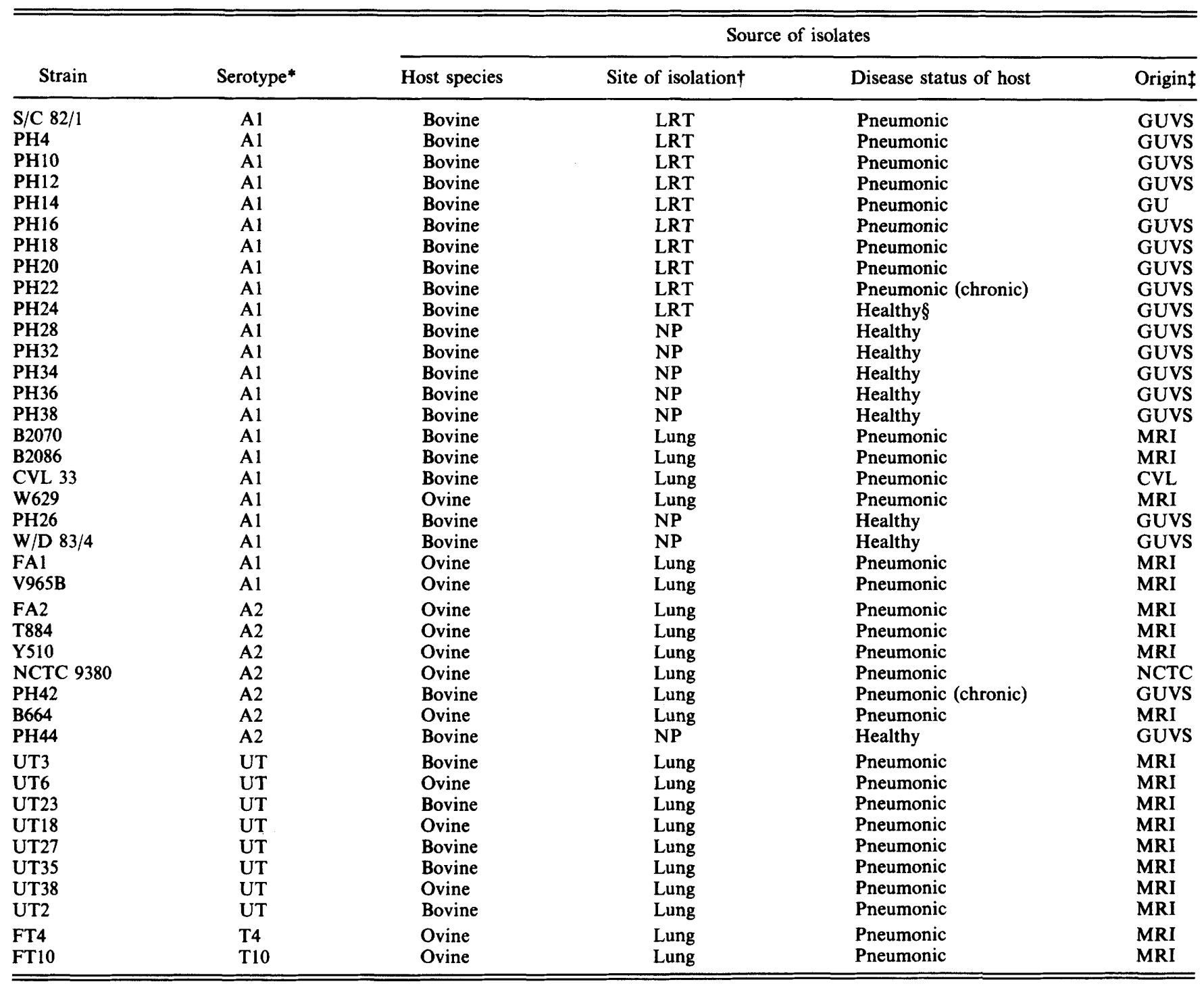

- UT, untypable.

† LRT, lower respiratory tract; NP, nasopharynx.

‡ GUVS, Glasgow University Veterinary School; MRI, Moredun Research Institute, Edinburgh, UK; CVL, Central Veterinary Laboratory, Surrey.

$\S$ Healthy calf but in contact with pneumonic animals.

Bovine antiserum was raised against live cells of isolate $\mathrm{S} / \mathrm{C} 82 / 1$ in a Herefordshire calf as follows. Bacteria were grown overnight in BHIB, washed, resuspended in phosphate-buffered saline (PBS; $150 \mathrm{mM}$ $\mathrm{NaCl}, 7.2 \mathrm{mM}-\mathrm{Na}_{2} \mathrm{HPO}_{4}, 2.8 \mathrm{mM}-\mathrm{NaH}_{2} \mathrm{PO}_{4}, \mathrm{pH} 7.2$ ) to $10^{9}$ c.f.u. $\mathrm{ml}^{-1}$ and mixed with an equal volume of Freund's incomplete adjuvant; $6 \mathrm{ml}$ volumes of the mixture $\left(3 \times 10^{9}\right.$ c.f.u. $)$ were injected intramuscularly on days $0,14,35$ and 57 and the animal was bled on day 67 after weekly test-bleeding.

Cross absorption of antisera. Rabbit anti-S/C 82/1 and -W/D 83/4 LPS antisera were cross-absorbed with cells of isolates W/D 83/4 and S/C $82 / 1$, respectively. Bacteria were grown overnight in $100 \mathrm{ml}$ of BHIB, harvested, washed in PBS and resuspended in $3 \mathrm{ml}$ of the same buffer. Cells from a $1 \mathrm{ml}$ sample of this cell suspension were harvested in a microcentrifuge, and resuspended in $1 \mathrm{ml}$ of a 1 in 4 dilution of the antiserum in PBS. After incubation at $37^{\circ} \mathrm{C}$ for $2 \mathrm{~h}$, the cells were removed by centrifugation and the process was repeated twice more with fresh cells. The antiserum was filter-sterilized through a $0.22 \mu \mathrm{m}$ Millipore filter and finally stored at $-70^{\circ} \mathrm{C}$.

SDS-PAGE. LPS was separated by SDS-PAGE using $15 \%(\mathrm{w} / \mathrm{v}$, acrylamide) resolving gels incorporating $4 \mathrm{M}$-urea as described previously (Davies et al., 1991). The LPS was visualized by silver-staining using the method of Tsai \& Frasch (1982). Smooth Escherichia coli O:111 B4 or rough Salmonella typhimurium TV119 Ra mutant LPSs (Sigma) were used as controls.

Western blotting. After separation by SDS-PAGE, the LPS was transferred to nitrocellulose membranes by the method of Towbin et al. (1979) in a Bio-Rad Trans-Blot Cell. Transfer was carried out overnight 
at $15 \mathrm{~V}$ in buffer containing $25 \mathrm{mM}$-Tris/ $\mathrm{HCl}, 192 \mathrm{~mm}$-glycine and $20 \%$ $(\mathrm{v} / \mathrm{v})$ methanol ( $\mathrm{pH} \mathrm{8.3)}$, then at $30 \mathrm{~V}$ for 4-5 h. After completion of transfer, the nitrocellulose membranes were washed (three $10 \mathrm{~min}$ washes) in PBS ( $\mathrm{pH} 7.4$ ). Non-specific binding was blocked by incubation for $1 \mathrm{~h}$ in $2.5 \%$ (w/v) fat-free dried skimmed milk in PBS containing $0.15 \%(\mathrm{v} / \mathrm{v})$ Tween-20, the membranes washed (three $10 \mathrm{~min}$ washes) in PBS containing $0.15 \%(\mathrm{v} / \mathrm{v})$ Tween-20, and incubated for $1 \mathrm{~h}$ in blocking buffer containing the test serum diluted 1 in 200. After three $10 \mathrm{~min}$ washes in PBS, the membranes were incubated for $1 \mathrm{~h}$ with horseradish-peroxidase-labelled rabbit antibovine or goat anti-rabbit IgG (Sigma) diluted 1 in 1000 in blocking buffer. The membranes were washed again in PBS (three $10 \mathrm{~min}$ washes) and developed in a substrate solution containing $0.03 \%(w / v)$ 3,3'-diaminobenzidine tetrahydrochloride (Sigma), 0.02\% (w/v) $\mathrm{CoCl}_{2}$ and $0.1 \%$ hydrogen peroxide.

\section{Results}

Optimal conditions for the analysis of $P$. haemolytica LPS, including a reproducible and convenient method of LPS preparation, an electrophoresis system giving optimal resolution, and the most effective staining procedure, have been determined previously (Davies $e t$ al., 1991). In the present study, the LPS profiles of $40 P$. haemolytica isolates were examined after preparation of LPS by digestion of outer membranes with proteinase $K$, followed by separation in $15 \%$ gels containing $4 \mathrm{M}$-urea and staining by the method of Tsai \& Frasch (1982). Analysis of the LPS in this way revealed 10 distinct profiles among the biotype $A$ and untypable isolates which were designated LPS types 1-10, respectively. Representative examples of these LPS profiles are shown in Fig. 1 and the distribution of the LPS types among the isolates is shown in Table 2. It should be noted that the resolution of the low-molecular-mass regions in Fig. 1 is poor due to deliberate over-development with the silverstain to allow for adequate visualization of the highmolecular-mass bands (see Davies et al., 1991).

Serotype Al isolates, which were predominantly of bovine origin, comprised three LPS types: two of these were smooth, LPS types 1 and 2, and one was rough, LPS type 3 (Fig. 1, lanes 1-6). The majority of the Al isolates (19/23) were of LPS type 1 (Fig. 1, lanes 1 and 2), two isolates were of LPS type 2 (Fig. 1, lanes 3 and 4) and a further two isolates were of LPS type 3 (Fig. 1, lanes 5 and 6). Type 1 and 2 LPS appeared identical in the highmolecular-mass regions of silver-stained gels, where similar ladder-patterns were evident in both cases, but differed in the low-molecular-mass region, both in the number of bands present and in their relative mobilities (see also Davies et al., 1991). However, the ladderpattern in these LPS types was not as pronounced and did not have as many bands as did the ladder-patterns of the smooth-type LPS of the T4 and T10 P. haemolytica isolates or of $E$. coli (compare with lanes 19, 20 and 22,
Table 2. LPS types and immunotypes of the P. haemolytica isolates examined in the study

\begin{tabular}{|c|c|c|c|c|}
\hline \multirow[b]{2}{*}{ Isolate } & \multirow[b]{2}{*}{ Serotype } & \multicolumn{3}{|c|}{ LPS } \\
\hline & & Chemotype* & PAGE type & Immunotype \\
\hline $\mathrm{S} / \mathrm{C} 82 / 1$ & Al & $\mathbf{S}$ & 1 & 1 \\
\hline PH4 & Al & $\mathbf{S}$ & 1 & 1 \\
\hline PH10 & A1 & $\mathbf{S}$ & 1 & 1 \\
\hline PH12 & Al & $\mathbf{S}$ & 1 & 1 \\
\hline PH14 & Al & $\mathbf{S}$ & 1 & 1 \\
\hline PH16 & $\mathrm{Al}$ & $\mathbf{S}$ & 1 & 1 \\
\hline PH18 & Al & $\mathbf{S}$ & 1 & 1 \\
\hline PH20 & Al & $\mathbf{S}$ & 1 & 1 \\
\hline PH22 & Al & $\mathbf{S}$ & 1 & 1 \\
\hline PH24 & Al & $\mathbf{S}$ & 1 & 1 \\
\hline PH28 & Al & $\mathbf{S}$ & 1 & 1 \\
\hline PH32 & Al & $\mathbf{S}$ & 1 & 1 \\
\hline PH34 & Al & $\mathbf{S}$ & 1 & 1 \\
\hline PH36 & Al & $\mathbf{S}$ & 1 & 1 \\
\hline PH38 & Al & $\mathbf{S}$ & 1 & 1 \\
\hline B2070 & Al & $\mathbf{S}$ & 1 & 1 \\
\hline B2086 & A1 & $\mathbf{S}$ & 1 & 1 \\
\hline CVL 33 & Al & $\mathbf{S}$ & 1 & 1 \\
\hline W629 & Al & $\mathbf{S}$ & 1 & 1 \\
\hline PH26 & $\mathrm{Al}$ & $\mathbf{S}$ & 2 & 2 \\
\hline W/D $83 / 4$ & Al & $\mathbf{S}$ & 2 & 2 \\
\hline FA1 & Al & $\mathbf{R}$ & 3 & 3 \\
\hline V965B & Al & $\mathbf{R}$ & 3 & 3 \\
\hline FA2 & A2 & $\mathbf{R}$ & 3 & 3 \\
\hline T884 & A2 & $\mathbf{R}$ & 3 & 3 \\
\hline Y510 & A2 & $\mathbf{R}$ & 3 & 3 \\
\hline NCTC 9380 & $\mathrm{~A} 2$ & $\mathbf{R}$ & 3 & 3 \\
\hline PH42 & A2 & $\mathbf{R}$ & 3 & 3 \\
\hline B664 & $\mathrm{A} 2$ & $\mathbf{R}$ & 4 & - \\
\hline PH44 & A2 & $\mathbf{R}$ & 5 & - \\
\hline UT3 & UT & $\mathbf{S}$ & 1 & 1 \\
\hline UT6 & UT & $\mathbf{S}$ & 1 & 1 \\
\hline UT23 & UT & $\mathbf{S}$ & 6 & - \\
\hline UT18 & UT & $\mathbf{S}$ & 7 & - \\
\hline UT27 & UT & $\mathbf{R}$ & 8 & - \\
\hline UT35 & UT & $\mathbf{S}$ & 9 & - \\
\hline UT38 & UT & $\mathbf{S}$ & 9 & - \\
\hline UT2 & UT & $\mathbf{R}$ & 10 & - \\
\hline FT4 & $\mathrm{T} 4$ & $\mathbf{S}$ & - & - \\
\hline FT10 & T10 & $\mathbf{S}$ & - & - \\
\hline
\end{tabular}

- S, smooth-type LPS; R, rough-type LPS.

respectively). Type 3 LPS was different in that it did not possess a high-molecular-mass ladder-pattern. The lowmolecular-mass region of this LPS type was, however, very similar to that of LPS type 1, with the exception that a minor band present in the latter was missing from the type 3 LPS.

The LPS profiles of the seven serotype A2 isolates examined were all of the rough chemotype and consisted of three types. The majority of the isolates $(5 / 7)$ possessed LPS which was identical to the type 3 LPS of the serotype A1 isolates (Fig. 1, lanes 7 and 8). The remaining two isolates each had a unique profile, however, which differed in the relative mobilities of low-molecular-mass components; these were designated LPS types 4 and 5, respectively (Fig. 1, lanes 9 and 10). 


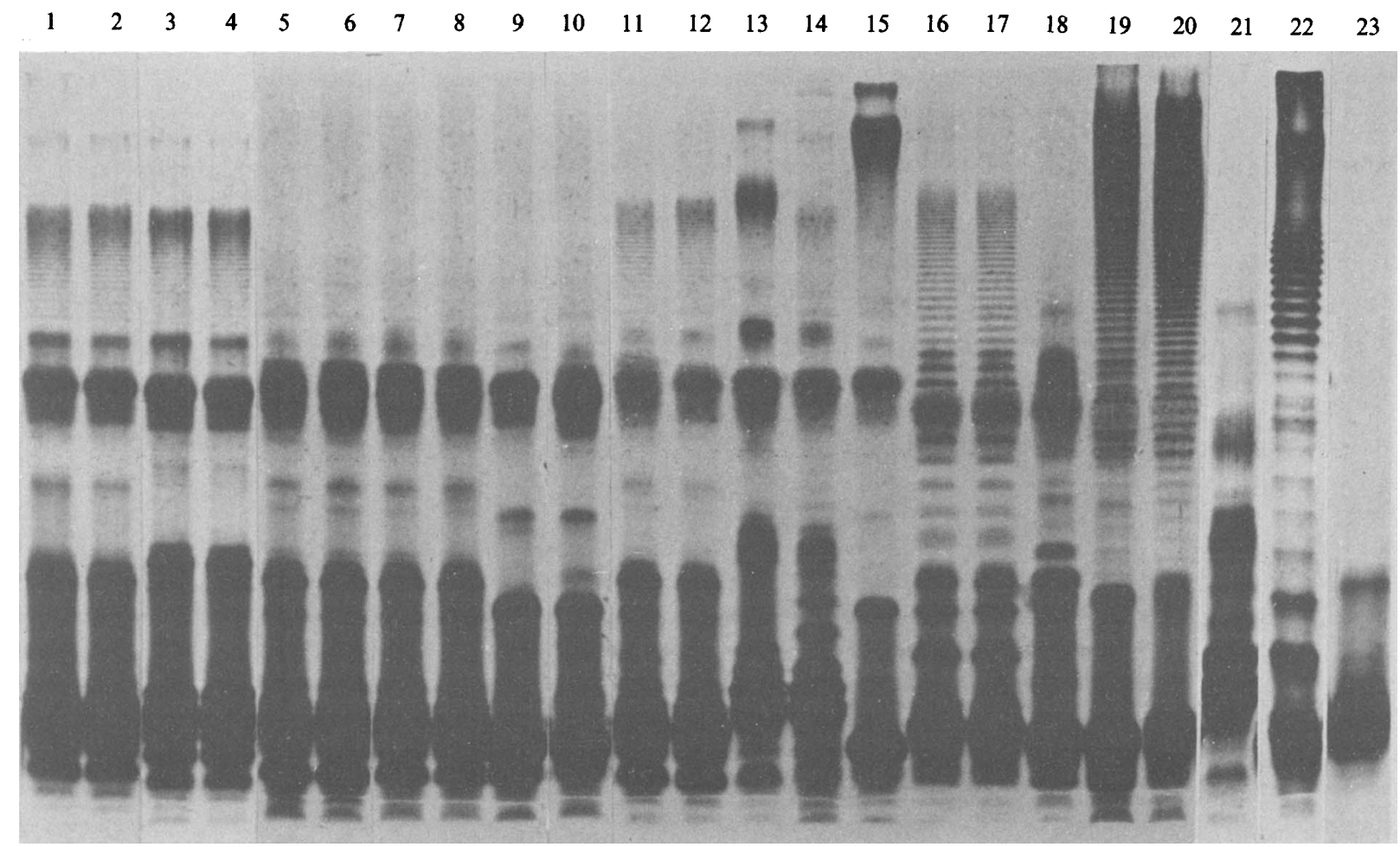

Fig. 1. LPS profiles of selected $P$. haemolytica isolates showing the various LPS types. Lane 1 , isolate S/C 82/1 (A1), LPS type 1 ; lane 2 , isolate W629 (A1), LPS type 1; lane 3, isolate W/D 83/4 (A1), LPS type 2; lane 4, isolate PH26 (A1), LPS type 2; lane 5, isolate FA1 (A1), LPS type 3; lane 6, isolate V965B (A1), LPS type 3; lane 7, isolate FA2 (A2), LPS type 3; lane 8, isolate PH42 (A2), LPS type 3; lane 9, isolate B664 (A2), LPS type 4; lane 10, isolate PH44, LPS type 5; lane 11, isolate UT6 (UT), LPS type 1; lane 12, isolate UT3 (UT), LPS type 1; lane 13, isolate UT23 (UT), LPS type 6; lane 14, isolate UT18(UT), LPS type 7; lane 15, isolate UT27 (UT), LPS type 8; lane 16, isolate UT35 (UT), LPS type 9; lane 17, isolate UT38 (UT), LPS type 9; lane 18, isolate UT2 (UT), LPS type 10; lane 19, isolate FT4 (T4); lane 20, isolate FT10 (T10); lane 21, P. multocida NCTC 10322; lane 22, E. coli O111:B4; lane 23 S. typhimurium TV119 (Ra).

The eight untypable isolates demonstrated greater variation in LPS profiles than did the other isolates and consisted of six distinct LPS types, including four smooth and two rough (Fig. 1, lanes 11-18). Two of these isolates, UT3 and UT6, had LPS identical to the type 1 LPS of the serotype A1 isolates (Fig. 1, lanes 11 and 12). The remaining LPS types, designated types 6-10, had profiles which differed in both the low-molecular-mass and high-molecular-mass regions. Isolates UT23, UT18, UT35 and UT38 had smooth LPS profiles, the last two being identical; these were designated LPS types 6, 7 and 9 , respectively (Fig. 1, lanes 13, 14, 16 and 17). Isolates UT27 and UT2 had rough LPS profiles which were designated LPS types 8 and 10, respectively (Fig. 1, lanes 15 and 18). P. multocida NCTC 10322 had a characteristic rough LPS profile (Fig. 1, lane 21) whereas the LPS of E. coli B4 and S. typhimurium TV119 had the expected smooth and rough profiles, respectively (Fig. 1, lanes 22 and 23).

The antigenic relatedness of the different LPS types was examined by transferring each LPS to nitrocellulose and probing with bovine or rabbit anti-type 1 LPS antisera. It should be noted that although the bovine serum was raised against whole cells, only anti-LPS antibodies were detected since LPS was the only component present on the nitrocellulose. Reactions of representative LPS types with bovine and rabbit antitype 1 LPS antisera are shown in Fig. 2(a) and Fig. 2(b), respectively. Bovine anti-type 1 LPS antiserum (Fig. 2a) reacted strongly with both high- and low-molecular-mass components of type 1 LPS from both the serotype A1 isolates (lanes 1 and 2) and the untypable isolates (lanes 11 and 12). This pattern of antibody recognition was designated immunotype 1 . The bovine anti-type 1 LPS antiserum also reacted strongly with the high-molecularmass components of type 2 LPS but there was a weaker response to the low-molecular-mass components (Fig. $2 a$, lanes 3 and 4). This pattern of antibody recognition was designated immunotype 2 . The antiserum reacted strongly to the low-molecular-weight components of the rough type 3 LPS of both A1 isolates (Fig. $2 a$, lanes 5 and 6) and $\mathrm{A} 2$ isolates (Fig. $2 a$, lanes 7 and 8). In addition, the pattern of antibody recognition in the low-molecularmass region was the same for both the type 1 and 3 LPS. 


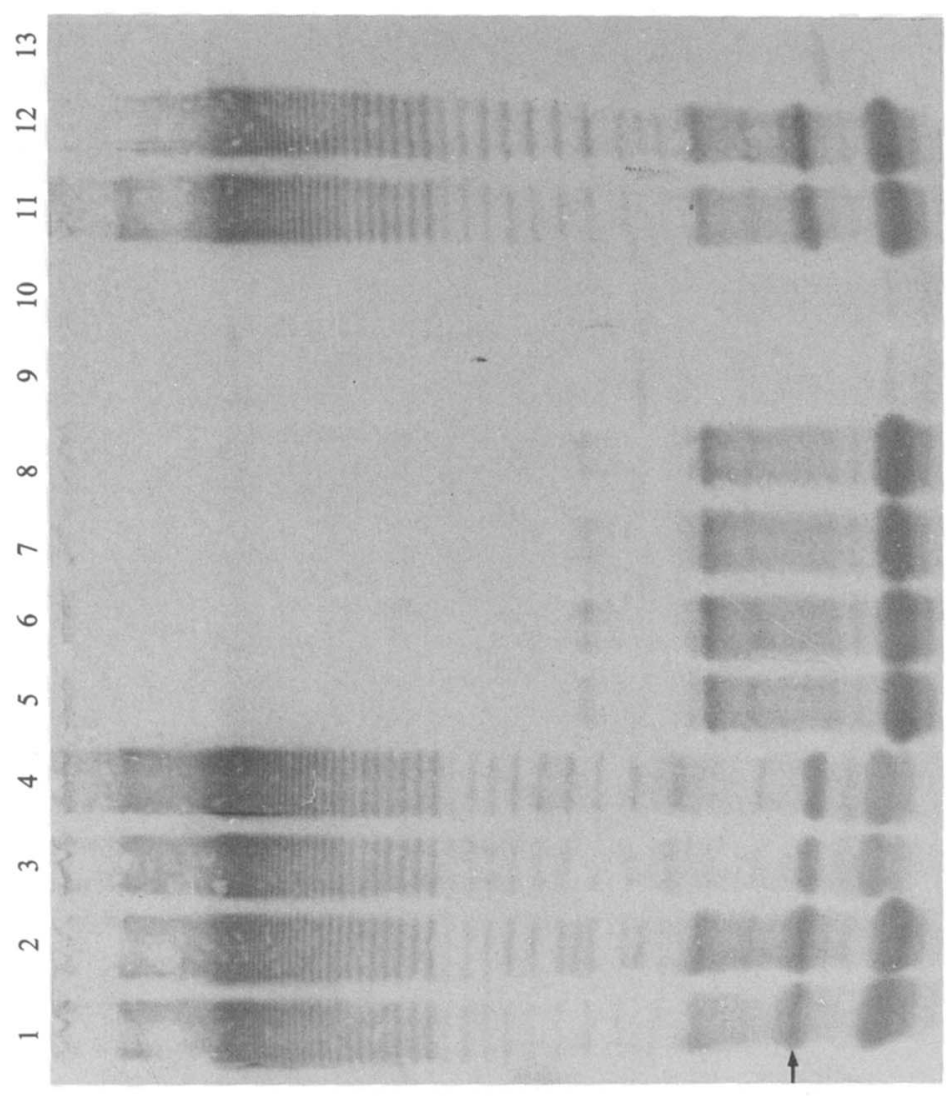

녕 边芒政 施品

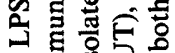
..

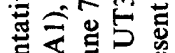
我 응 记 造 \& 要全这 要过讨

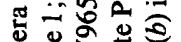
政 类 记

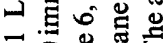
政 인 겅 ส a 吾要

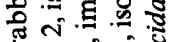
ฐ

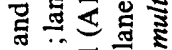
डิ 눙

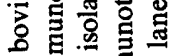

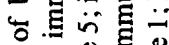

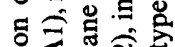
产交余

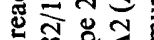

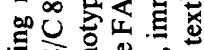
的焉官

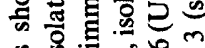
今. 음

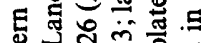
过嵒总 3 :

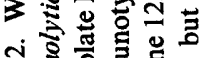

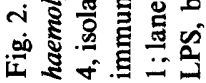


(a)

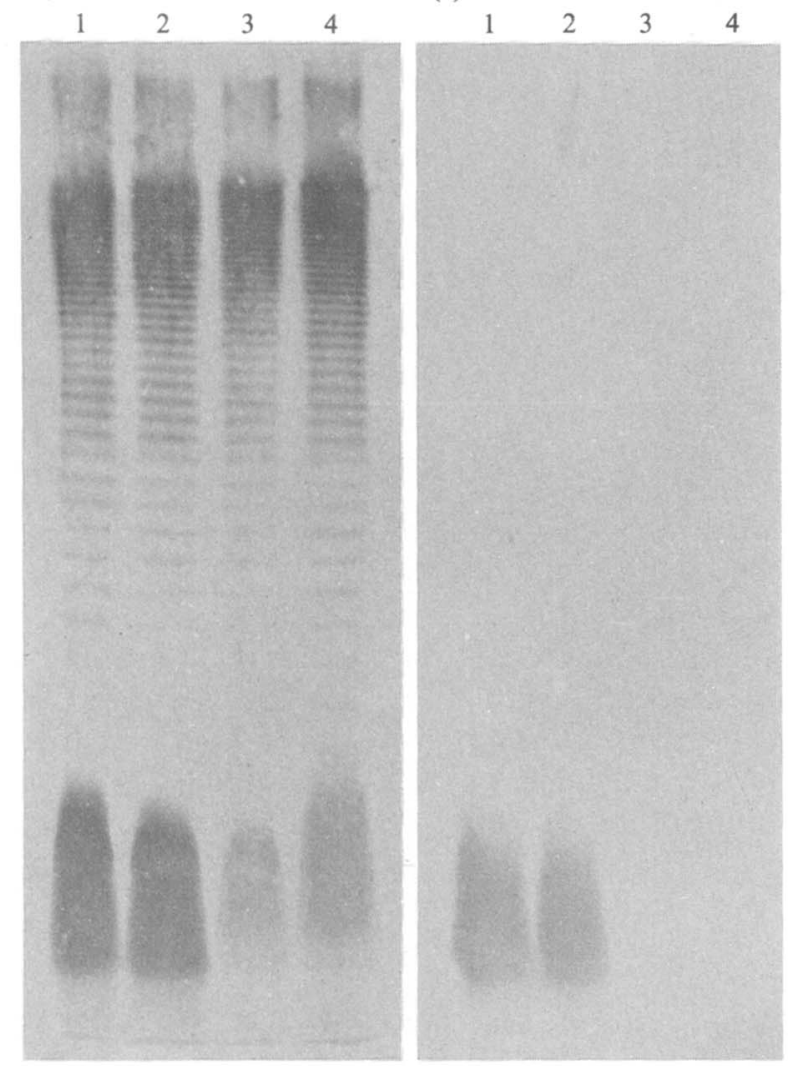

Fig. 3. Western blots showing reactions of selected LPS types with unabsorbed (a) and cross-absorbed (b) rabbit anti-type 1 LPS antiserum. Anti-S/C 82/1 (type 1 LPS) antiserum was cross-absorbed with cells of isolate W/D 83/4 (type 2 LPS). Isolates examined were S/C 82/1, type 1 LPS (lane 1); W629, type 1 LPS (lane 2); PH26, type 2 LPS (lane 3 ) and W/D 83/4, type 2 LPS (lane 4).

This pattern of antibody recognition was designated immunotype 3 . However, there was no or negligible reactivity to all of the other LPS types including those of types 4 and 5 , from the other serotype A2 isolates (Fig. $2 a$, lanes 9 and 10), as well as to the LPS of other species incuding $P$. multocida (Fig. $2 a$, lane 13). Similar results were obtained when rabbit anti-type 1 LPS antiserum was used to probe the same purified LPS samples (Fig. 2b). However, in this case there was a stronger response to low-molecular-mass components of type 2 LPS, including the recognition of a component which was present in both type 1 and 2 LPS but not in type 3 LPS (Fig. $2 b$; arrowed). The absence of this band in type 3 LPS was in agreement with its absence from the SDSPAGE profiles. An additional feature was the more extensive ladder-pattern in the lower half of the gel. These results are summarized in Table 2 .

To confirm that the low-molecular-mass components of type 1 and 2 LPS were different, unabsorbed and cross-absorbed anti-type 1 and anti-type 2 LPS rabbit (a)

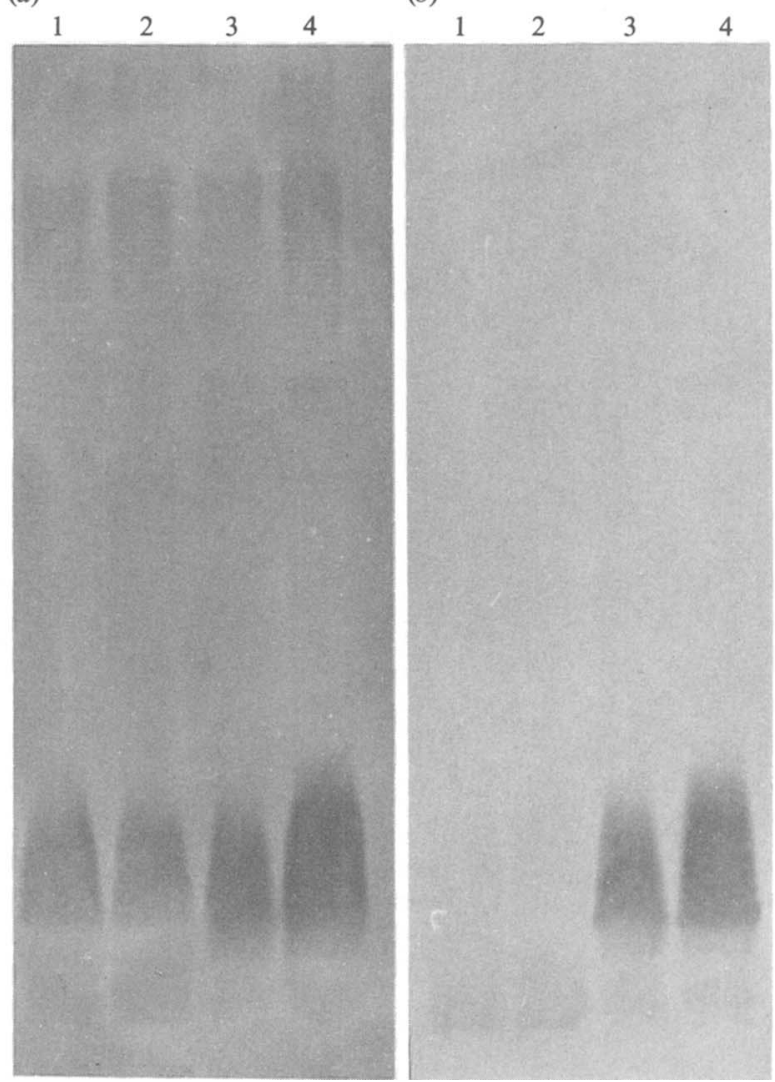

Fig. 4. Western blots showing reactions of selected LPS types with unabsorbed $(a)$ and cross-absorbed $(b)$ rabbit anti-type 2 LPS antiserum. Anti-W/D 83/4 (type 2 LPS) antiserum was cross-absorbed with cells of isolate S/C 82/1 (type I LPS). Isolates examined were the same as in Fig. 3.

antisera were compared (Figs 3 and 4). Fig. 3(a) shows the reactions of unabsorbed anti-type 1 antiserum with type 1 (lanes 1 and 2) and type 2 (lanes 3 and 4) LPS. As expected, there was an identical reaction to the highmolecular-mass components of both LPS types but a weaker response to the low-molecular-mass components of the type 2 LPS compared to the type 1 LPS. After cross-absorption of this antiserum with heterologous cells, having type 2 LPS (W/D 83/4), the reaction to the high-molecular-mass components was completely removed for both LPS types (Fig. $3 b$ ). However, although the reaction to the low-molecular-mass components of type 2 LPS was completely removed (Fig. $3 b$, lanes 3 and 4 ), there still remained some reactivity to the type 1 LPS (Fig. $3 b$, lanes 1 and 2). Similar results were obtained when anti-type 2 LPS antiserum was cross-absorbed with heterologous cells having type 1 LPS (S/C 82/1) (Fig. 4). In this case, cross-absorption caused complete removal of reactivity to both high- and low-molecular-mass components of type 1 LPS (Fig. $4 b$, lanes 1 and 2) as well as removal of reactivity to high-molecular-mass components of type 2 LPS, but there remained substantial 
reactivity to the low-molecular-mass components of type 2 LPS (Fig. 4b, lanes 3 and 4).

\section{Discussion}

The objective of this study was to examine and compare, by SDS-PAGE and Western blotting, the LPS of a relatively large number of serotype $\mathrm{A} 1, \mathrm{~A} 2$ and untypable $P$. haemolytica isolates, including isolates from diseased and healthy cattle or sheep. The possibility of capsular polysaccharide interfering with the LPS profiles was unlikely because this material, being polymeric in nature and having a high molecular mass, is unlikely to pass into the gel during SDS-PAGE. In addition, the fact that isolates of different capsular serotypes had identical LPS profiles, for example those of LPS type 3, confirmed that the capsular polysaccharide did not influence the LPS profiles. Ten different LPS profiles were identified among the biotype $\mathrm{A}$ and untypable isolates examined, including five smooth-type and five rough-type profiles; these were designated LPS types 1-10. LPS types 1 and 2 were both smooth-type LPSs with apparently identical $\mathrm{O}$-antigen side-chains but with different core-oligosaccharide regions. LPS type 3 was rough, not possessing Oantigen side-chains, but its core-oligosaccharide region was similar, although not identical, to that of type 1 LPS. Among the serotype Al isolates, the majority (19/23) possessed LPS of type 1; two isolates possessed type 2 LPS, and the remaining two isolates possessed type 3 LPS. The majority (5/7) of the serotype A2 isolates possessed LPS of type 3 whereas the remaining two A2 isolates each had a unique rough LPS type, i.e. types 4 and 5 .

The untypable isolates examined in the present study, comprising LPS types $1,6,7,8,9$ and 10 , were representative of seven of the nine serogroups, plus one additional serogroup, identified by Donachie et al. (1984) using counter current immunoelectrophoresis. Four of these LPS types were of the smooth form $(1,6,7$ and 9) and two of the rough form (8 and 10). These untypable isolates were also included in a study by Bisgaard \& Mutters (1986) who identified, by conventional phenotypic characterization, nine biogroups among 116 isolates of $P$. haemolytica. Isolates belonging to biotype A (with the exception of serotype All isolates) were grouped together as biogroup 1, whereas the T4, T10 and T15 isolates were grouped together as biotype 2 . With the exception of two isolates, the untypable isolates of Donachie et al. (1984) were placed in biogroups 5, 6, 7 or 9. The two exceptions were isolates UT3 and UT6, the isolates identified as having type 1 LPS in the present study, which were classed within biogroup 1 . Thus, the present LPS analysis confirmed the relationship between these two untypable isolates and the A1 and A2 isolates of biogroup 1 of Bisgaard \& Mutter (1986). In addition, the analysis has gone a stage further and has demonstrated a relationship between these two isolates and a subgroup of serotype A1 isolates possessing the common type 1 LPS.

The Western blotting results confirmed the observations made by SDS-PAGE analysis of LPS profiles. Immunologically, the O-antigen side-chains of LPS types 1 and 2 were identical, whereas the core-oligosaccharide regions were different, although there was some crossreactivity between these regions. The core-oligosaccharide region of the type 3 LPS was immunologically very similar, but not identical, to that of LPS type 1, as was expected from the similarities of their SDS-PAGE profiles. Differences in the core-oligosaccharide regions of these two LPS types were revealed when rabbit, but not bovine, anti-type 1 LPS antiserum was used. Thus, these three LPS types are very similar to each other, yet differ in fundamental ways. All other LPS types examined were immunologically non-reactive and hence unrelated to these three types. The chemical basis of these differences is currently under investigation.

Until recently (Davies et al., 1991; Utley et al., 1992), the possession of O-antigen side-chains had not clearly been demonstrated in $P$. haemolytica strains other than in those of biotype T (Adlam, 1989). Although reference was made to 'smooth' and 'rough' LPS of $P$. haemolytica serotypes A7 and A1, by Rimsay et al. (1981) and Emau et al. (1987), respectively, these authors did not provide indisputable evidence for the possession of O-antigen side-chains, such as by showing SDS-PAGE profiles. The smooth LPS profiles of the Al isolates examined in the present study differed from those of the serotype T4 and T10 isolates in that the former were less densely stained, consisted of less numerous and narrower bands distributed over a smaller length of the gel and were immunologically distinct. However, it was also apparent that Western blotting revealed a more widespread and distinctive ladder-pattern in these Al isolates than did silver-staining, as can be seen by comparing Fig. 1 with Fig. 2(b). Such differences in the detection of LPS sidechains between silver-staining and Western blotting have been described previously in the LPS of $E$. coli (Karch et al., 1984), Coxiella burnetii (Hackstadt et al., 1985) and Campylobacter jejuni (Preston \& Penner, 1987). The differences observed between the LPS of the biotype $A$ and $T$ isolates provide further evidence that these two groups should be regarded as different species (Biberstein \& Francis, 1968; Bisgaard \& Mutters, 1986).

LPSs possessing $\mathrm{O}$-antigen side-chains are uncommon in certain groups of bacteria inhabiting mucosal surfaces such as the respiratory and genito-urinary tracts. For example, bacteria such as Neisseria meningitidis (Tsai et 
al., 1983), Neisseria gonorrhoeae (Mandrell et al., 1986), Bordetella pertussis (Peppler, 1984), Haemophilus influenzae (Inzana, 1983) and P. multocida (Lugtenberg et al., 1984) all possess rough-type LPS, although of a different form, termed lipooligosaccharide, to the rough LPS of the Enterobacteriaceae. In biotype A strains of $P$. haemolytica, there appears to be greater variation in the core-oligosaccharide region of the LPS than in the Oantigen side-chain region, since only one type of $\mathrm{O}$ antigen was identified in the present study as opposed to at least four types of core-oligosaccharide. This suggests that the LPS of this organism is possibly more like the lipooligosaccharides of the bacteria described above, where there is extensive intraspecies variation in the core-oligosaccharide region, than like that of the Enterobacteriaceae, where there is greater uniformity in this region. In a recent study of the structure of the LPS of C. jejuni, Aspinall et al. (1992) demonstrated that some serotypes of this organism are unusual in possessing a core structure similar to the lipooligosaccharides of Neisseria and Haemophilus species and O-antigen sidechains similar to those of Salmonella smooth-type LPS. It is possible that the type 1 and 2 LPSs of $P$. haemolytica may also be unusual in having a lipooligosaccharide-type core region as well as O-antigen side-chains and this is being investigated further. The possession of $\mathrm{O}$-antigen side-chains by a bacterium causing a respiratory infection is unusual, although not exceptional, since Pseudomonas aeruginosa also possesses LPS with $\mathrm{O}$-antigen sidechains (Rivera et al., 1988). Although the biotype T strains of $P$. haemolytica possess a smooth-type LPS it is notable that these strains are primarily responsible for a systemic infection, rather than a respiratory infection, of sheep (Gilmour \& Gilmour, 1989).

Whereas the majority of serotype A1 isolates having type 1 LPS originated from diseased cattle, those having type 2 LPS originated from the nasopharynx of healthy cattle and those having type 3 LPS originated from sheep (Table 3). Serotype A2 isolates are predominantly associated with disease in sheep and it was perhaps a significant finding that two of the three serotype Al isolates from sheep had the same rough-type 3 LPS characteristic of five of the A2 isolates, four of which were also from sheep. In addition, it should be noted that the two bovine serotype A2 isolates, PH42 and PH44, although possessing rough-type LPSs (types 3 and 5, repectively), were associated with a chronic pneumonic case and a healthy animal, respectively, and not with acute disease. The study provided preliminary evidence, therefore, that certain LPS types may be associated with disease in cattle or sheep, respectively, and that the capsular type may not be as important as was previously thought. The results suggested that rough LPS types, and type 3 LPS in particular, are primarily associated with
Table 3. Relationship between LPS types and immunotypes of $P$. haemolytica isolates examined in the study, and host species and health status of the host

Serotypes of isolates (A1, A2 or untypable) are given in parentheses.

\begin{tabular}{|c|c|c|c|c|c|}
\hline \multirow{3}{*}{$\begin{array}{l}\text { LPS } \\
\text { type }\end{array}$} & \multirow{3}{*}{$\begin{array}{c}\text { Immuno- } \\
\text { type }\end{array}$} & \multicolumn{4}{|c|}{ No. of isolates } \\
\hline & & \multicolumn{2}{|c|}{ Bovine* } & \multicolumn{2}{|c|}{ Ovine } \\
\hline & & Pneumonic $\dagger$ & Healthy & Pneumonic & Healthy \\
\hline \multirow[t]{2}{*}{1} & 1 & $12(\mathrm{~A} 1)$ & $6(\mathrm{~A} 1)$ & I (A1) & - \\
\hline & 1 & 1 (UT) & - & 1 (UT) & - \\
\hline 2 & 2 & - & 2 (A1) & - & - \\
\hline \multirow[t]{3}{*}{3} & 3 & 1 (A2) & - & - & - \\
\hline & 3 & - & - & $2(\mathrm{~A} 1)$ & - \\
\hline & 3 & - & - & 4 (A2) & - \\
\hline 4 & - & - & - & 1 (A2) & - \\
\hline 5 & - & - & $1(\mathrm{~A} 2)$ & - & - \\
\hline 6 & - & 1 (UT) & - & - & - \\
\hline 7 & - & - & - & 1 (UT) & _- \\
\hline 8 & - & 1 (UT) & - & - & - \\
\hline 9 & - & 1 (UT) & - & - & - \\
\hline 10 & - & 1 (UT) & - & 1 (UT) & _- \\
\hline
\end{tabular}

* Host species. † Disease status of host.

acute pneumonia in sheep whereas smooth LPS, predominantly of type 1 , is associated with acute pneumonia in cattle. The fact that LPS type 3 was associated with both serotypes A1 and A2 in sheep isolates, but was not identified in any bovine isolates, suggests that this LPS type may have an important role in the pathogenesis of ovine pneumonic pasteurellosis. The core-oligosaccharide regions of LPS types 1 and 3 were, with the exception of a single band, identical. The major difference between these two LPS types was that the former possessed Oantigen side-chains whereas the latter did not. This suggests that the possession of $\mathrm{O}$-antigen side-chains may be important in bovine pneumonic pasteurellosis whereas the absence of the $\mathrm{O}$-antigen chains may be of importance in ovine pneumonic pasteurellosis. The relevance of these observations to studies on epidemiology is obvious but their relevance to pathogenesis warrants further study.

In conclusion, this study has demonstrated previously unrecognized differences in the LPS of $\boldsymbol{P}$. haemolytica. It has been shown that, within a given serotype, different LPS types may occur and isolates of different serotypes may possess the same LPS type. These results were not unexpected, especially when our knowledge of similar variation in other species is taken into consideration. For example, in E. coli, strains of different O-serotypes occur within a given capsular serogroup and, similarly, strains of the same O-serotype occur having different capsular types (Ørskov \& Ørskov, 1984). In addition, a possible relationship is suggested between type 1 LPS and pneumonic pasteurellosis in cattle, and type 3 LPS and pneumonic pasteurellosis in sheep, although further 
studies are required to confirm this. The findings reported here, which have implications for both epidemiological and virulence studies, are being expanded by analysis of the LPS of a larger number of isolates including additional serotypes.

Q. Ali was supported by a scholarship from the Ministry of Science and Technology, Pakistan; R. L. Davies was supported by AFRC grant AG $17 / 529$.

\section{References}

Aarsleff, B. E., Biberstein, L., Shreeve, B. J. \& Thompson, D. A. (1970). A study of untypable strains of Pasteurella haemolytica. Journal of Comparative Pathology 80, 493-498.

ADlaM, C. (1989). The structure, function and properties of cellular and extracellular components of Pasteurella haemolytica. In Pasteurella and Pasteurellosis, pp. 75-92. Edited by C. Adlam \& M. J. Rutter. London: Academic Press.

Aspinall, G. O., McDonald, A. G., Raju, T. S., Pang, H., Mills, S. D., Kurjanczyk, L. A. \& Penner, J. L. (1992). Serological diversity and chemical structures of Campylobacter jejuni lowmolecular-weight lipopolysaccharides. Journal of Bacteriology 174, 1324-1332.

Biberstein, E. L. (1978). Biotyping and serotyping of Pasteurella haemolytica. Methods in Microbiology 10, 252-269.

Biberstein, E. L. \& Francis, C. K. (1968). Nucleic acid homologies between the A and T types of Pasteurella haemolytica. Journal of Medical Microbiology 1, 105-108.

Biberstein, E. L., GilLs, M. \& KNIGHT, H. (1960). Serological types of Pasteurella haemolytica. Cornell Veterinarian 50, 283-300.

BISGAARD, M. \& MUTTERs, R. (1986). Re-investigations of selected bovine and ovine strains previously classified as Pasteurella haemolytica and description of some new taxa within the Pasteurella haemolytica-complex. Acta Pathologica Microbiologica et Immunologica Scandinavica B 94, 185-193.

Carter, G. R. (1967). Pasteurellosis: Pasteurella multocida and Pasteurella haemolytica. Advances in Veterinary Science 11, 321-379.

Chengappa, M. M., Carter, G. R. \& Bailie, W. E. (1984).Comparison of indirect haemagglutination and rapid plate agglutination tests with counterimmunoelectrophoresis for typing Pasteurella haemolytica. Journal of Clinical Microbiology 20, 660-663.

Davies, R. L., Ali, Q., Parton, R., CoOte, J. G., Gibbs, A. \& Freer, J. H. (1991). Optimal conditions for the analysis of Pasteurella haemolytica lipopolysaccharide by sodium dodecyl sulphate-polyacrylamide gel electrophoresis. FEMS Microbiology Letters 90, 2328.

Donachie, W., Fraser, J., Quirie, M. \& Gilmour, N. J. L. (1984). Studies on strains of Pasteurella haemolytica not typable by the indirect haemagglutination test. Research in Veterinary Science 37, 188-193.

Durham, J. A., Antone, S. M., Cunningham, M. W. \& Confer, A. W. (1988). Monoclonal antibodies to Pasteurella haemolytica serotype 1 lipopolysaccharide: demonstration of antigenic similarities among several serotypes. Journal of Clinical Microbiology 26, 885-889.

EmaU, P., Giri, S. N. \& Bruss, M. L. (1987). Effects of smooth and rough Pasteurella haemolytica lipopolysaccharides on plasma cyclicnucleotides and free fatty acids in calves. Veterinary Microbiology 15 , 279-292.

Fodor, L., Vara, J., HaJtos, J., Donachie, W. \& Gilmour, N. J. L. (1988). Characterization of a new serotype of $P$. haemolytica isolated in Hungary. Research in Veterinary Science 44, 399.

FraNk, G. H. (1980). Serological groups among untypable bovine isolates of Pasteurella haemolytica. Journal of Clinical Microbiology 12, 579-582.

Frank, G. H. \& Wessman, G. E. (1978). Rapid plate agglutination procedure for serotyping Pasteurella haemolytica. Journal of Clinical Microbiology 7, 142-145.
Gilmour, N. J. L. \& Gilmour, J. S. (1989). Pasteurellosis of sheep. In Pasteurella and Pasteurellosis, pp. 223-262. Edited by C. Adlam \& M. J. Rutter. London: Academic Press.

Hackstadt, T., Peacock, M. G., Hitchcock, P. J. \& Cole, R. L. (1985). Lipopolysaccharide variation in Coxiella burnetii: intra-strain heterogeneity in structure and antigenicity. Infection and Immunity 48, 359-365.

HitchCock, P. J. \& Brown, T. M. (1983). Morphological heterogeneity among Salmonella lipopolysaccharides chemotypes in silver-stained polyacrylamide gels. Journal of Bacteriology 154, 269-277.

HitchCock, P. J., Leive, L., Makela, H., Rietschel, E. T., StrittMATTER, W. \& MORRISON, D. C. (1986). Lipopolysaccharide nomenclature - past, present and future. Journal of Bacteriology 166 , 699-705

INZANA, T. J. (1983). Electrophoretic heterogeneity and interstrain variation of the lipopolysaccharide of Haemophilus influenzae. Journal of Infectious Diseases 148, 492-499.

KarCH, H., Leying, H. \& OpFerkUCh, W. (1984). Analysis of electrophoretically heterogeneous lipopolysaccharides of Escherichia coli by immunoblotting. FEMS Microbiology Letters 22, 193-196.

LEITCH, R. A. \& RichaRdS, J. C. (1988). Structure of the O-chain of the lipopolysaccharide of Pasteurella haemolytica serotype T3. Biochemistry and Cell Biology 66, 1055-1065.

Lugtenberg, B., BOXTel, R. \& DeJong, M. (1984). Atrophic rhinitis in swine: correlation of Pasteurella multocida pathogenicity with membrane proteins and lipopolysaccharide patterns. Infection and Immunity 46, 48-54.

Mandrell, R., Schneider, H., Apicella, M., Zollinger, W., Rice, P. A. \& GRIFFISS, J. M. (1986). Antigenic and physical diversity of Neisseria gonorrhoeae lipooligosaccharides. Infection and Immunity 54, 63-69.

Manning, P. J., NaAsz, M. A., Delong, D. \& Leary, S. L. (1986) Pasteurellosis in laboratory rabbits: characterisation of lipopolysaccharides of Pasteurella multocida by polyacrylamide gel electrophoresis, immunoblot technique, and enzyme-linked immunosorbant assay. Infection and Immunity 53, 460-463.

ØRSKOV, F. \& ØRSKOV, I. (1978). Serotyping of Enterobacteriaceae, with special emphasis on $\mathrm{K}$ antigen determination. Methods in Microbiology 11, 1-77.

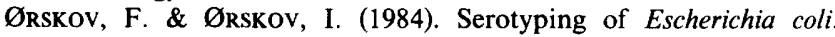
Methods in Microbiology 14, 43-112.

PePpler, M. S. (1984). Two physically and serologically distinct lipopolysaccharide profiles in strains of Bordetella pertussis and their phenotype variants. Infection and Immunity 43, 224-232.

PERRY, M. B. \& BabIUK, L. A. (1984). Structure of polysaccharide chain of Pasteurella haemolytica (serotype 4) lipopolysaccharide. Canadian Journal of Biochemistry and Cell Biology 62, 108-114.

Preston, M. A. \& Penner, J. L. (1987). Structural and antigenic properties of lipopolysaccharides from serotype reference strains of Campylobacter jejuni. Infection and Immunity 55, 1806-1812.

RichaRDS, J. C. \& LeITCH, R. A. (1989). Elucidation of the structure of the Pasteurella haemolytica serotype T10 lipopolysaccharide O-antigen by N. M. R. spectroscopy. Carbohydrate Research 186, 275-286.

RIMLER, R. B. (1990). Comparison of Pasteurella multocida lipopolysaccharides by sodium dodecyl sulfate-polyacrylamide gel electrophoresis to determine relation between group $B$ and $E$ hemorrhagic septicemia strains and serologically related group A strains. Journal of Clinical Microbiology 28, 654-659.

Rimsay, R. L., Coyle-Dennis, J. E., Lauerman, L. H. \& Souire, P. G. (1981). Purification and biological characterization of endotoxin fractions from Pasteurella haemolytica. American Journal of Veterinary Research 42, 2134-2138.

Rivera, M., Bryan, L. E., Hancock, R. E. W. \& McGroarty, E. J (1988). Heterogeneity of lipopolysaccharide from Pseudomonas aeruginosa. Analysis of lipopolysaccharide chain length by gel filtration and sodium dodecyl sulfate-polyacrylamide gel electrophoresis. Journal of Bacteriology 170, 512-521.

Shreeve, B. J., Biberstein, E. L. \& Thompson, D. A. (1972). Variation in carrier rates of Pasteurella haemolytica in sheep. II. Diseased flocks. Journal of Comparative Pathology 82, 111-118. 
Sturm, S., Fortnagel, P. \& Timmis, K. N. (1984). Immunoblotting procedure for the analysis of electrophoretically-fractionated bacterial lipopolysaccharide. Archives of Microbiology 140, 198-201.

Towbin, H., STaehelin, T. \& GoRdon, J. (1979). Electrophoretic transfer of proteins from polyacrylamide gels to nitrocellulose sheets: procedure and some applications. Proceedings of the National Academy of Sciences of the United States of America 76, 4350-4354.

TSAI, C.-M. \& Frasch, C. E. (1982). A sensitive silver stain for detecting lipopolysaccharides in polyacrylamide gels. Analytical Biochemistry 119, 115-119.
TSAI, C. M., Boykins, R. \& Frasch, C. E. (1983). Heterogeneity and variation among Neisseria meningitidis lipopolysaccharide. Journal of Bacteriology 155, 498-504.

Tsai, C.-M., MocCa, L. F. \& Frasch, C. E. (1987). Immunotype epitopes of Neisseria meningitidis lipooligosaccharide types 1 through 8. Infection and Immunity 55, 1652-1656.

Utley, S. R., Bhat, U. R., BYRD, W. \& KaDIS, S. (1992) Characterization of lipopolysaccharides from four Pasteurella haemolytica serotype strains: evidence for presence of sialic acid in serotypes 1 and 5. FEMS Microbiology Letters 92, 211-216. 